\title{
ABRIENDO LAS PUERTAS DE LA HISTORIA: PROPUESTA DE "HISTORIA A DEBATE" PARA UN NUEVO PARADIGMA DIDÁCTICO'
}

\author{
ABRINDO AS PORTAS DA HISTÓRIA: \\ PROPOSTA DE "HISTORIA A DEBATE" PARA UM NOVO PARADIGMA DIDÁTICO \\ OPENING THE HISTORY OF DOORS: \\ PROPOSED "HISTORY DEBATE" A NEW PARADIGM FOR TEACHING
}

Domingo Marrero Urbín ${ }^{2}$

\begin{abstract}
RESUMEN: Este trabajo, que se estructura de acuerdo a los componentes tradicionales del currículo (objetivos, contenidos, metodología y evaluación), es sobre todo una propuesta de currículo practicado y por tanto es también un currículo "soñado", pero no por ello utópico o inalcanzable. De hecho, el actual currículo reglado de historia en España constituye un marco favorable en que llevarlo a cabo, aunque todavía oponga algunos obstáculos, especialmente su alto grado de especificación de los contenidos.
\end{abstract}

Palabras clave: Currículo. Aprendizaje histórico. Relación teoría y la práctica.

RESUMO: Este trabalho está estruturado de acordo com os componentes tradicionais do currículo (objetivos, conteúdos, metodologia e avaliação), considera o currículo como prática, portanto, é um currículo "utópico", mas não irrealista ou inatingível. Trata do currículo de história atual regulamentado na Espanha, que permite a ação, mas vê que ainda há alguns obstáculos para sua implementação, especialmente seu alto grau de especificação do conteúdo.

Palavras-chave: Currículo. Aprendizagem histórica. Relação teoria e prática.

\begin{abstract}
This work is structured according to the traditional components of the curriculum (objectives, contents, methodology and evaluation), considers the curriculum as practice, therefore, is a "utopian" curriculum, but not unrealistic or unattainable. It deals with the current history curriculum regulated in Spain that allows the action, but sees that there are still some obstacles to its implementation, especially its high content specification.
\end{abstract}

Keywords: Curriculum. Historical learning. Relationship theory and practice.

\footnotetext{
${ }^{1}$ Ver apresentação deste número da revista, bem como a Proposta de um Novo Paradigma Educativo do grupo Historia a http://www.histedbr.fe.unicamp.br/revista/edicoes/28/art01_28.pdf

2 Instituto de Educación Secundaria Lila, Gran Canaria, España Diplomado en Profesorado de EGB, Licenciado en Historia (con Memoria de Licenciatura desde 1993, publicada en 1996), y profesor de Enseñanza Secundaria (1992). Doctorado Historiografía y Metodología de la Investigación.
} 


\section{Introducción}

El objetivo de estas páginas es presentar una propuesta de nuevo paradigma educativo de la historia desde y para los principios que la comunidad historiográfica de Historia a Debate ( $\mathrm{HaD}$ ) ha ido consensuando durante dos largas e intensas décadas. Desde ese punto de vista su propósito es "revolucionar" las prácticas dominantes de enseñanza de la historia, y no tanto las ideas: los presupuestos teóricos de $\mathrm{HaD}$ y de este trabajo nacieron en el siglo XIX y se desarrollaron a lo largo del XX.

En la historia de la ciencia es muy corriente y lógico que las teorías nazcan antes que sus prácticas y que éstas vayan incorporando plenamente las nuevas ideas tras un periodo de tiempo razonable. Sin embargo, el ámbito de las prácticas docentes suele oponer mayor resistencia a la innovación, hasta el punto no de retrasar más de lo normal el desarrollo de las nuevas teorías en las aulas, sino de impedirlo del todo, incluso contra las normas educativas. Esto pone de relieve una dificultad conceptual añadida: la existencia de varios tipos paralelos de currículo.

Por su naturaleza, este documento está obligado a ofrecer un cierto grado de apertura, señalando los aspectos más susceptibles de discusión. Pero también precisa alguna clase de concreción. En consecuencia, el primer y más extenso epígrafe se centra en la crítica de la enseñanza dominante, oponiéndola a las indicaciones del currículo reglado y a los principios epistemológicos y psicopedagógicos en que éste se asienta, no sin algunos desaciertos. En la medida que la evaluación del aprendizaje está íntimamente ligada a los objetivos de la enseñanza, la crítica del actual modelo de evaluación se integra en el subapartado sobre los objetivos de la enseñanza tradicional.

Los demás epígrafes de este trabajo se ocupan de la propuesta de nuevo paradigma educativo. Y se estructuran igualmente según los elementos esenciales del currículo. Asimismo incorpora lo relativo a la evaluación en las reflexiones sobre los objetivos, aunque otra parte se aborda en el último, sobre la metodología. En esta propuesta el trabajo del alumnado es la principal fuente de instrumentos de evaluación del aprendizaje. 


\section{Lo que la enseñanza y el aprendizaje de la historia no deberían ser: las malas prácticas}

Tratándose de realizar una propuesta de nuevo modelo de la didáctica de la historia, coherente e integrado en el paradigma historiográfico que HaD supone, lo más pertinente es presentar una formulación "en positivo". Y a esa tarea están destinados los demás epígrafes de este trabajo.

De hecho, es muy difícil hallar una definición de "malas prácticas" de la didáctica de la historia y de la enseñanza en general. Alguien ha escrito que esta dificultad obedece al deseo de eludir aproximaciones al problema posiblemente ofensivas para una parte de los docentes. Pero, sin menoscabar la verosimilitud de ese argumento, la inexistencia de un "catálogo de malas prácticas" también posee fundamentos materiales: las prácticas docentes reales son el objeto menos abordado por la investigación didáctica.

En el sentido inverso, esa debilidad de la producción científica sobre la enseñanza de la historia afecta igualmente a las propuestas de "buenas prácticas", algo más numerosas que sus antípodas. Algunas de ellas carecen del soporte empírico necesario que las avale, sustentándose en experiencias aisladas "de laboratorio". Y otras en ocasiones adolecen del rigor necesario para presentarse como tales, especialmente cuando han sido elaboradas por las propias administraciones educativas.

No faltan, sin embargo, pilares suficientemente sólidos en los que apoyar una propuesta de buenas prácticas. Y se deben buscar en las fuentes de currículo tradicionales: la propia epistemología de la historia, la psicopedagogía y la sociología de la educación. Sus aportaciones, en forma de principios, conceptos y métodos, constituyen el soporte de cualquier propuesta curricular. Y suelen infundir el sentido y el contenido de los currículos reglados, aunque no siempre con la misma calidad.

Por ello esas mismas fuentes (incluyendo los currículos reglados en la medida que su rigor lo permita) pueden y deben proporcionar los patrones básicos para definir las malas prácticas. Una tarea que también supone una exigencia ética y profesional: todo no vale o, al menos, no por igual. 


\subsection{Unos objetivos y una evaluación obsoletos}

En la práctica cotidiana de la enseñanza y el aprendizaje de la historia todavía subyace un objetivo fundamental que orienta y configura el resto de los elementos del currículo y que da sentido a la actividad de muchos profesores y alumnos en todas las etapas del Sistema Educativo (SE): la reproducción de un relato cerrado y ajeno. Aunque puede que su número se haya ido reduciendo paulatinamente en las últimas décadas, es la experiencia más común entre los estudiantes de historia.

Opera como un objetivo oculto, entre otras razones porque no está representado en los currículos reglados. Pero se manifiesta con total nitidez en el momento de la evaluación, cuando la mayoría de nuestros estudiantes preparan sus exámenes memorizando literalmente los temas, o sus resúmenes, sobre los que deberán demostrar que "han aprendido". Unas pruebas que, además, constituyen su principal ( $y$ a veces único) instrumento de evaluación y calificación en la mayoría de los casos. Sólo que, como ellos mismos suelen reconocer abiertamente, y sus profesores constatar inevitablemente, lo han olvidado casi todo muy pocos días después.

En España, la Ley General de Educación (LGE) de 1970, infundida por las teorías conductistas y la enseñanza basada en la actividad, ya supuso una primera ruptura con la reproducción del conocimiento como fin primordial del proceso de aprendizaje, al menos en la Enseñanza General Básica (EGB). Ese nuevo modelo imprimió una finalidad muy distinta al esfuerzo de profesores y alumnos, que ya no estaría dirigido a la simple reproducción del saber, sino a su ejecución práctica. Esto significó también un cambio en la relación del sujeto que aprende con el conocimiento, en este caso histórico. Aunque los estudiantes siguieron subordinados a un objeto ajeno a su actividad productora, su manipulación práctica les proporcionó un cierto grado de emancipación mediante su aprehensión material.

Veinte años después, la Ley Orgánica General del Sistema Educativo (LOGSE), deudora del constructivismo, introdujo un hilo conductor del proceso de enseñanza y aprendizaje muy diferente, en la enseñanza primaria y también la secundaria obligatoria: los alumnos deberían construir su propio conocimiento. Con esto el objetivo final del acontecer diario en las aulas debía situarse en el extremo opuesto 
a la mera reproducción. Y sobre todo significó una relación definitivamente emancipadora del estudiante con el saber.

A lo largo de este proceso, los currículos reglados de historia en Bachillerato y en la Universidad no sufrieron una transformación tan significativa como los de las etapas precedentes. Paralelamente el día a día de las aulas de historia pudo ver algunos cambios, como la realización de un mayor número de ejercicios prácticos. De cualquier modo, esos ejercicios ocupaban (y lo siguen haciendo) un espacio más o menos marginal en la evaluación, que siguió teniendo en el examen su principal protagonista. En definitiva, no se produjo un cambio real en el fin último de la mayor parte del esfuerzo de profesores y alumnos, que continuó siendo la reproducción.

En eso coinciden muchos informes y estudios de las propias universidades realizados sobre todo a partir de la segunda mitad de la década pasada: al menos en los centros superiores la lección magistral y el examen (propios del modelo reproductivo del saber) seguían siendo las estrategias de enseñanza y evaluación más extendidas. El detonante de esos estudios fue el "proceso Bolonia" en las universidades, que ha supuesto modificaciones sustanciales en todos los aspectos de la vida académica, incluyendo los currículos.

Con independencia de la fuerte oposición inicial que generó ese proceso, y que subsiste al menos parcialmente, en el ámbito curricular significó la introducción de un nuevo principio rector del proceso de enseñanza y aprendizaje: el desarrollo competencial del alumnado, que tampoco ha estado exento de severas críticas, como las formuladas por Carlos Barros. Al mismo tiempo los currículos de todas las etapas preuniversitarias españolas sufrieron una modificación más en el mismo sentido, con la introducción de un nuevo elemento, las Competencias Básicas (CCBB).

Por primera vez en muchas décadas, los currículos reglados de todo el SE poseen un hilo conductor común en el desarrollo competencial del alumnado. Su formulación inicial y su posterior evolución han sido y siguen siendo objeto de rechazo y de controversia, que se abordará en el próximo epígrafe. Pero, al margen del debate, se ha ido abriendo paso la idea de que las CCBB significan una nueva vuelta de tuerca en el abandono definitivo del paradigma reproductivo del saber, porque se persigue la construcción progresivamente autónoma del conocimiento 
por los propios estudiantes, profundizando en una relación emancipadora con él. Y el profesorado de todas las etapas está constatando, de peor o mejor grado, que la evaluación ha dado asimismo un giro copernicano.

\subsection{Un saber varias veces cerrado}

Ese conocimiento sigue siendo también objeto (o víctima) de malas prácticas por varios motivos, aunque su denominador común es la "cerrazón", que le afecta en varios aspectos esenciales. El "producto histórico" que circula por nuestras aulas desde Primaria a la Universidad es un objeto generalmente ajeno a su propia naturaleza, a las características de su proceso de producción, y a la realidad y los intereses del alumnado, aunque probablemente todo esto suceda menos en los centros superiores.

En primer lugar, los estudiantes han de afrontar una sucesión lineal de temas bien diferenciados y secuenciados cronológicamente. La combinación de estos dos criterios de organización de los contenidos ocasiona unos efectos indeseables de no poca importancia. La primacía del criterio temporal persigue una cierta fidelidad al desarrollo de la historia misma, pero ignora algo elemental: el simple transcurso de los años y los siglos no es por sí mismo un motor de la historia. Sin embargo, las transformaciones que los diversos sujetos históricos llevan a cabo en sus relaciones económicas, sociales, políticas... sí lo son. Por ello el tiempo histórico es "elástico", sufriendo aceleraciones y desaceleraciones provocadas por fenómenos y procesos de muy desigual naturaleza y duración.

La compartimentación en temas dedicados a periodos sobre los que "se debe contarlo todo" (como, por ejemplo, un reinado) rompe los procesos de media y larga duración y sus relaciones de causalidad, o los hace muy poco visibles, dificultando la construcción de la gran explicación histórica. El apego al desarrollo de los acontecimientos a lo largo del tiempo termina por minimizar los vínculos entre fenómenos de distintas épocas, limitándose a la causalidad más o menos inmediata o a la sincrónica.

Y cuando la asignatura incluye el tiempo presente (como sucede por ejemplo en $4^{\circ}$ de ESO o en la Historia del Mundo Contemporáneo de Bachiller) en la mayoría de los casos no es finalmente estudiado, porque pocos docentes consiguen "terminar el temario". Y en el caso de quiénes lo logran, la compartimentación 
hace del presente un tiempo históricamente inexplicable, sin vínculos con el pasado, que no va más allá de la Segunda Guerra Mundial.

Sin embargo, desde hace dos décadas, con los currículos de la LOGSE, Ios contenidos históricos aparecen agrupados en grandes bloques y no en simples temas. Aunque el acierto en la configuración concreta de esos bloques pudiera ser discutible, el objetivo de esta estrategia organizativa, explícito en las orientaciones iniciales de los documentos curriculares, no es otro que favorecer el estudio de los grandes procesos, los que trascienden las fronteras de las décadas y los siglos, los que hacen comprensible la historia en su conjunto, incluyendo el mismo presente.

La desaparición de los temas tradicionales de los currículos oficiales pretende igualmente promover la transversalidad intrahistórica e interdisciplinar, con temas como la mujer, el trabajo, o el desarrollo científico y tecnológico, por citar algunos ejemplos, que obligan a bucear en toda la historia para su tratamiento. Pero ésa sigue siendo una experiencia mayoritariamente desconocida para nuestros estudiantes.

La renuncia al estudio de los grandes temas históricos en las aulas hace que, en segundo lugar, la asignatura continúe siendo un dominio de la historia relato. La hegemonía del hecho frente al proceso y del relato frente a la explicación aleja hasta hacerla imperceptible la posibilidad de afrontar la historia como un problema. En las aulas el pasado no se problematiza, no se discute. $Y$, menos aún, se cuestiona el presente. Su ausencia de las aulas no sólo obedece a que el mundo actual y sus conflictos no se enseñen, aunque figuren en los currículos reglados de varias asignaturas de historia. También es una consecuencia directa del predominio del relato, que deja sin explicación histórica muchos de los grandes desafíos que ha vivido la Humanidad, en cualquier etapa de su evolución.

Pero el relato no sólo impide problematizar la realidad histórica, pasado y presente, también lo hace con el conocimiento que de ella tenemos. Así, en tercer lugar, nuestros estudiantes se encuentran con un saber histórico concluso, con un producto definitivamente acabado, no sujeto a posible modificación y discusión. Hace algo más de medio siglo, Thomas Kuhn ya advertía que los manuales escolares ocultan la controversia inherente a la evolución del conocimiento científico, que se produce por medio de revoluciones protagonizadas por nuevos paradigmas en ascenso. 
En el caso de la historia enseñada cotidianamente, la razón fundamental de este problema es que los procesos de producción del conocimiento rara vez forman parte de los contenidos de las asignaturas. Lo más común es que los estudiantes que han concluido el Bachillerato de Humanidades lo ignoren casi todo sobre las fuentes y los métodos. Como consecuencia terminan desarrollando una visión estática del saber histórico, un objeto cerrado a las nuevas investigaciones y enfoques, o a algo tan simple como los nuevos hallazgos.

Para combatir esta carencia, los currículos de la LOGSE incluyeron hace ya veinte años un bloque de contenidos sobre procedimientos, que suponían practicar en el aula el método de investigación. Ese bloque desapareció de los currículos actualmente vigentes. Pero fue sustituido por otro, denominado "contenidos comunes", que implica igualmente el desarrollo de procesos de indagación en el aula. Y las orientaciones iniciales del Ministerio de Educación son muy explícitas sobre su función: indican el modo en que el alumnado debe aprender los demás contenidos.

Obviamente, en los centros universitarios la problemática relativa a la producción del conocimiento histórico como objeto de aprendizaje es otra. Hasta las reformas impuestas por el Plan Bolonia, el alumnado generalmente estudiaba estos contenidos (en un sentido "teórico" y "práctico") en asignaturas específicas que se impartían en los últimos cursos, en ocasiones con carácter optativo. Estas materias y la realización de algunos sencillos trabajos para otras asignaturas constituían todas las oportunidades ( $y$ todo el bagaje) del alumnado para enfrentarse a la investigación y sus problemas. La hoy vigente enseñanza competencial implica la elaboración de más trabajos prácticos, pero ello no garantiza necesariamente un aprendizaje adecuado de los conocimientos más pertinentes sobre la producción del saber histórico.

Prácticamente lo mismo puede afirmarse sobre el aprendizaje de las diversas escuelas o paradigmas historiográficos en las aulas universitarias. Sin embargo, su ausencia es total en las de Secundaria y también en sus currículos reglados. Cabe suponer que la supuesta complejidad conceptual de estudiar la diversidad de pensamientos historiográficos lo justifica. Pero sólo en parte, porque también se ignora el pensamiento histórico de los estudiantes, muy vinculado al mundo de los valores, pese a las indicaciones en ese sentido de los currículos oficiales desde la 
época de la LOGSE. Aunque esa limitación obedece en mayor cuantía a las malas prácticas metodológicas.

\subsection{La enseñanza expositiva y el libro de texto}

Con la aprobación de aquella ley orgánica el pensamiento del alumnado debió convertirse en el centro de la actividad cotidiana del aula, porque el aprendizaje consiste básicamente en su redimensionamiento y transformación, según las tesis constructivistas que dieron sustento teórico a la LOGSE y a los currículos que la desarrollaron. Así que la detección y conocimiento iniciales de las "ideas previas" de los estudiantes por sus profesores debieron hacerse imprescindibles en el aula.

Pero ni su publicación en el BOE, ni la formación recibida por decenas de miles de enseñantes fueron suficientes para transformar sus ideas y sus prácticas docentes. Y la necesidad de comenzar el proceso de enseñanza y aprendizaje a partir del pensamiento de los estudiantes se materializó durante los primeros años en unos cuestionarios iniciales "de conocimientos previos" (escasamente procedimentales y casi enciclopédicos) con la pretensión de establecer "el nivel del alumnado". La mayoría del profesorado siguió concibiendo a sus alumnos como recipientes (unos más "colmados" que otros) que se debían rellenar con nuevos conocimientos. Y para ello, nada mejor que el método expositivo en sus diversas variantes, unas más vinculadas a la enseñanza no universitaria y otras a la superior.

En las universidades, hasta las reformas propiciadas por el Plan Bolonia, la lección magistral fue la metodología hegemónica, apoyada generalmente en unos "apuntes" más o menos oficiales de la asignatura como recurso más destacado y, en no pocas ocasiones, único. Desde entonces han proliferado los trabajos prácticos que deben realizar los estudiantes. Pero no es seguro que constituyan proyectos de investigación histórica, por muy sencillos que pudieran ser. Ésos seguramente han quedado relegados al final de los estudios. $Y$, por ello, tampoco es seguro que hayan generado una auténtica transformación del pensamiento histórico de sus jóvenes autores.

En las etapas preuniversitarias de muy poco sirvió que (con la LOGSE) la indagación en el aula como estrategia general de enseñanza y aprendizaje se hallase explícita en varios de los objetivos y criterios de evaluación, y en el 
conjunto de los contenidos procedimentales. Y está por ver, especialmente en las asignaturas de historia, la efectividad real de que los currículos ahora vigentes también la incluyen en sus objetivos y evaluación, y en sus contenidos comunes.

En estos niveles la enseñanza sigue siendo esencialmente expositiva. La lección magistral continúa practicándose profusamente, si bien su duración se ha acortado notablemente para alternarla con algunos ejercicios, lo que hace más viable la perpetuación del modelo. A ello contribuye la sustitución parcial o total de las explicaciones del profesor por la lectura en clase del libro de texto, durante la que generalmente el profesorado señala a sus estudiantes los contenidos más significativos. $Y$ es en el libro de texto donde igualmente encuentran las actividades que deben realizar y, últimamente, las específicas para su desarrollo competencial.

Así el libro de texto persiste en su papel de protagonista principal de las clases de historia. Aunque se trata de un simple recurso es, como lo ha sido desde hace muchas décadas, la guía rectora del proceso de enseñanza y aprendizaje, llegando a relegar completamente las indicaciones de las administraciones educativas, cuya consulta sigue siendo accesoria para muchos docentes. La prevalencia de los textos escolares en las aulas es uno de los mejores exponentes del predomino de la enseñanza expositiva de la historia. Y sus características estructurales lo hacen responsable preferente de la cerrazón de la historia enseñada.

La penetración masiva de las Tecnologías de la Información y la Comunicación (TIC) en los centros de enseñanza durante la última década se ha visto reflejada en los nuevos currículos. La competencia relativa al desenvolvimiento del alumnado en el mundo digital supone un primer reconocimiento de su importancia como recurso en el desarrollo del aprendizaje, poniendo el acento en los procesos de investigación, desde la búsqueda de información hasta la producción de síntesis finales en diversos formatos digitales por los estudiantes. En eso insisten, con desigual calidad, los objetivos y criterios de evaluación y los contenidos de los currículos reglados actualmente vigentes.

La "presión" de las TIC sobre el acontecer diario de las aulas ha dado inevitablemente algunos frutos. Pero todo parece indicar que las previsiones de los más optimistas se han ido al traste. Su creciente presencia e influencia en muchos aspectos de la actividad académica no ha promovido la transformación de las prácticas docentes, al menos como muchos esperaban. En términos generales no 
se ha producido una integración relevante de las TIC en los procesos de enseñanza y aprendizaje. No han conseguido desplazar al libro de texto, ni tampoco han liquidado la enseñanza expositiva. No en balde, la estrategia más exitosa de uso didáctico de las TIC es la proyección de presentaciones de diapositivas al alumnado.

\section{Enseñar historia para hacer futuro}

Es muy común entre los manuales de metodología asegurar que en muchas ocasiones los historiadores se adentran en un asunto del pasado con la intención de arrojar luz sobre un problema de su presente. Más allá del debate (en muchos aspectos ya superado) sobre si el tiempo presente y la actualidad son historiables, y más allá del interés (y hasta la pasión) que el pasado pueda suscitar por sí mismo, una convicción subyace en la gran mayoría de los historiadores: la principal función social del conocimiento histórico es permitir la comprensión de "los tiempos que corren". En parte ése es el sentido de la tradicional definición de la historia como "maestra de la vida".

La relación entre pasado y presente es esencial en el desarrollo de la historiografía desde sus mismos orígenes, situados usualmente en la Gracia Clásica. El mismo Herodoto de Halicarnaso consagró la mayor parte de su esfuerzo a su propia contemporaneidad, con independencia de los límites cronológicos impuestos por su predilección por las fuentes orales. Así que la comprensión del presente debería ser, en consecuencia, la primera finalidad de la enseñanza de la historia en cualquier etapa del SE.

No obstante, la comprensión global del campo de estudio propio nunca ha sido un fin en sí mismo para la totalidad de las disciplinas (más o menos "científicas") que la Humanidad ha ido desarrollando a lo largo de la historia, incluyendo las más especulativas, como la filosofía o la física teórica. Ese conocimiento constituye un medio, absolutamente imprescindible, para la auténtica finalidad de toda ciencia, que es la intervención en su parcela de la realidad en beneficio de los intereses hegemónicos en las sociedades humanas. Con ese objeto se crearon desde los primeros calendarios hasta las sondas espaciales que actualmente se hallan 
explorando nuestro sistema solar. El saber histórico tampoco ha sido ajeno a esa función, eminentemente "práctica", de todo conocimiento. Y es en este aspecto donde se ha producido un doble disenso, o un desacuerdo de dos caras, una histórica y otra historiográfica.

Hasta el siglo XIX, incluyendo a Ranke, el saber histórico fue un instrumento al servicio exclusivo de las élites, quiénes invariablemente la protagonizaban. La historia ensalzaba las gestas de los monarcas y de los nobles a su servicio, y condenaba o simplemente ignoraba a sus enemigos. La historia proporcionaba legitimidad a las casas reinantes, o se la restaba a las destronadas. La historia, en fin, prestaba el argumentario imprescindible en todas las disputas entre reyes o señores relativas a derechos y privilegios sobre territorios y gentes.

Pero el nacimiento y desarrollo del materialismo histórico a lo largo de la segunda mitad del siglo XIX y el todo el siglo XX, no sólo supuso la irrupción de "las masas" en la historia, representando un papel estelar, sino que el conocimiento histórico se convirtió en un instrumento revolucionario, al servicio de los intereses proletarios. Ya en el siglo XX, la Escuela de los Annales reforzó, desde otro enfoque historiográfico, esa "nueva historia". Por un lado, prosiguió la tarea de dar voz a "los sin voz" de todos los tiempos. Y, por otro, puso a su servicio ese saber como una herramienta para transformar el presente, para hacer futuro. Eso al menos se desprende del profundo compromiso político de sus miembros fundadores.

Sin embargo, el actual proceso de acumulación antidemocrática del poder político a escala global (o de construcción del "Imperio", según Hardt y Negri) desatado tras la caída del Muro de Berlín, y la consecuente efervescencia del paradigma neo/positivista hacen prácticamente imposible un consenso para reconocer la historia como un medio de construcción democrática de futuro. $Y$, con más reparos formales que de fondo, seguramente muchos docentes rechazarían que "enseñar a hacer futuro democráticamente" sea un objetivo primordial de su trabajo, empeñados como se hallan en "enseñar el pasado".

No obstante, es innecesario recordar la imperiosa necesidad de democratizar la historia que vive la Humanidad de esta segunda década del siglo XXI, y la voluntad popular de hacerlo puesta de manifiesto en decenas de países de todos los continentes durante los últimos años. Ni tampoco es necesario evocar el 
compromiso de $\mathrm{HaD}$ con esta tarea desde su mismo nacimiento. Un compromiso heredado de los paradigmas más relevantes del siglo $\mathrm{XX}$, explicitado en su Manifiesto, y profundizado en las ponencias sobre didáctica presentadas en sus congresos, en los debates específicos ("Qué historia enseñar", "Para qué estudiar historia", "Nuevo paradigma educativo"), y en algunos documentos básicos de Carlos Barros sobre didáctica.

Así, en su epígrafe XIV, sobre los fines de la historia, el Manifiesto de HaD es absolutamente inequívoco al subrayar la responsabilidad de los historiadores en que los sujetos de la historia construyan un futuro más humano para todos los hombres y mujeres del planeta. Igualmente, la necesidad de practicar una didáctica que eduque e instruya a los individuos y a la sociedad en su conjunto para hacer futuro mediante su acción en el presente se repite en muchas intervenciones de los diversos debates sobre enseñanza. $Y$ es particularmente recurrente en la discusión "Para qué estudiar historia", protagonizada en gran medida por estudiantes universitarios.

De la misma manera ese consenso se extiende a los documentos "más académicos": las ponencias sobre didáctica y los textos específicos de Carlos Barros acerca del mismo asunto. Entre las primeras, aquellas que abordan de un modo u otro las finalidades de la enseñanza de la historia coinciden explícita o implícitamente en valorar el conocimiento histórico como un instrumento fundamental para comprender el presente e intervenir en él. Entre los segundos, destaca las "Propuestas para el nuevo paradigma educativo de la historia" (2007). El profesor Barros señala la Escuela como un elemento decisivo en el desarrollo de la historia pública, donde aprender las relaciones mutuas entre el pasado y el presente, y entre el pasado y el futuro, y cómo el conocimiento de uno puede modificar la visión del otro. Más adelante añade que la enseñanza debe perseguir la comprensión histórica del presente educando a los estudiantes como sujetos históricos.

Sin duda alguna, es una tarea tan apremiante como laboriosa en todas las etapas del SE. No obstante, su complejidad es mayor en los centros superiores, debido al carácter específico de muchas asignaturas, ya sea por su parcelación temática como por su acotación cronológica. Aunque también es más 
trascendente, ya que en las aulas universitarias se forman todos los futuros docentes de historia.

En ese sentido, la introducción de la "enseñanza competencial" ha generado un debate acerca de las finalidades de la enseñanza de la historia: ¿enseñar historia para formar personas laboralmente más competentes? En esta controversia las competencias han aparecido comúnmente enfrentadas a los contenidos por una parte (¿enseñar competencias en vez de historia?), y por otra a los valores (¿ser laboralmente competente o ser un ciudadano comprometido con los valores humanos?). Sin embargo, ha sido un falso debate (al menos parcialmente) o una discusión fácilmente soluble básicamente por tres motivos, alguno de ellos avanzado por Carlos Barros.

Por un lado, el origen y la formulación inicial de las CCBB presentaban un sesgo neoliberal muy acusado, llegando a incluir una "competencia empresarial". Esto mereció severas críticas procedentes del ámbito educativo en muchos países europeos y extraeuropeos, que dieron sus frutos al menos en parte. Su revisión y configuración definitiva suscitaron menos discrepancias.

Por otro, la supuesta dicotomía entre competencias y valores se liquida si se considera la aptitud y la actitud de los sujetos para explicar históricamente el presente e intervenir en él desde valores humanos universales (la paz, la igualdad, la tolerancia...) como el principal indicador competencial. ¿Qué podría significar, si no, la "competencia histórica"? De esta manera, su esencia da la espalda al constructivismo filosófico (que pone el acento en la formación instrumental con menoscabo del conocimiento de la realidad) y se sitúa plenamente en el marco del constructivismo pedagógico.

Y, por último, tampoco hay espacio para la confrontación entre esas dos "patas del nuevo paradigma educativo" si se sitúa cada una en el elemento del currículo que le corresponde. $Y$ es que el problema de los valores se resuelve sobre todo en el ámbito de la selección y organización de los contenidos, y el concerniente al desarrollo competencial en el terreno metodológico, como ya ha apuntado el profesor Barros.

En cualquier caso, aún queda mucho trabajo por hacer. En primer lugar, habría que adaptar el enunciado y el contenido de nuestra "competencia histórica" a cada una de las etapas del SE. Qué significado tiene la comprensión histórica en los 
últimos cursos de Primaria, de qué clase de presente, cómo pueden los niños y niñas intervenir en él con una intención transformadora...

En segundo lugar, habría que desglosar en objetivos más concretos la "nueva finalidad" de la enseñanza de la historia aquí propuesta y, una vez más, hacerlo por etapas. Comprender el presente significa analizar y relacionar información procedente de diversas fuentes; reconocer, establecer y delimitar hechos y procesos, y sus interrelaciones mutuas; sintetizar en una exposición los nuevos conocimientos... Pero nada de esto puede llevarse a cabo por igual con niños de nueve años que con jóvenes de quince o de veinte.

Ello permitiría, en tercer lugar, identificar los diversos indicadores de nuestra competencia. Esos indicadores cumplirían dos funciones. Por un lado, constituirían los principales criterios de evaluación del aprendizaje de la asignatura. Y, por otro, permitirían establecer los vínculos con las CCBB generales, que cada docente debe evaluar con independencia de su asignatura, al menos en las etapas preuniversitarias.

La fijación de indicadores que desglosan comprensivamente las diversas CCBB en cada etapa aparenta ser contradictoria con el modelo constructivista, preocupado por los procesos cualitativos. En cierto modo, parece ser un tecnicismo más propio de la enseñanza por objetivos de los años 70, interesada en "medir" el avance de cada individuo a lo largo de la progresión del aprendizaje formalizada en unos "objetivos operativos". Sin embargo, esos indicadores facilitan la evaluación competencial, siempre compleja, desde una óptica también cualitativa. Y además favorecen una auténtica evaluación del aprendizaje, lejos de la simple calificación, que se hace del todo innecesaria: un viejo sueño de los movimientos de renovación pedagógica de hace cuatro décadas.

\section{Enseñar la relación entre pasado, presente y futuro: el hilo de Ariadna}

Asegura Carlos Barros que la tarea de los docentes de historia es enseñar el "análisis del presente a la manera de los historiadores". Para la mayoría de la población, incluyendo muchos estudiantes y unos cuantos de sus profesores, 
parecería una proposición intrínsecamente contradictoria: la historia se ocupa en exclusiva del pasado.

La clave que desactiva esa supuesta paradoja es que se trata de un estudio "histórico" del presente, que busca en el pasado sus raíces (cuando eso sea posible) y su evolución hasta llegar a la actualidad. Con ello el aula de historia de abre a la realidad del alumnado. ¿Pero qué clase de realidad? Si algo enseña la historia es que, aquí y allá, todos los presentes han sido y siguen siendo esencialmente problemáticos. Y si algo enseña la sociología de la educación es que el reto de resolver un problema constituye un notable factor de motivación. De esa manera el aula de historia se abre a los intereses del alumnado.

¿Y cuáles son esos "intereses"? Dos décadas de indagación -informal- en ellos proporcionan una lista más o menos invariable y recurrente de asuntos que los jóvenes de $4^{\circ}$ de ESO y de $1^{\circ}$ de Bachillerato han venido reconociendo como los principales problemas de "su mundo". Los más destacados son los relativos a la desigualdad mundial, social y de género, los conflictos y las guerras, los sistemas de gobierno, y la destrucción ambiental. A ellos se suman otros, igualmente trascendentes, pero atribuibles a fenómenos más coyunturales o de mayor impacto mediático, como los procesos migratorios, el terrorismo, la crisis económica... Así, el aula de historia se abre igualmente a los valores del alumnado, que se ven necesariamente involucrados e interrogados por esos grandes problemas de la Humanidad.

Un estudio de hace unos años efectuado en varios países europeos concluía que muy pocos profesores de historia consiguen terminar "su temario" antes de finalizar el año académico. Los motivos son diversos, aunque aquí las consecuencias son lo importante: el "recorte" de contenidos se hace casi siempre a costa de los últimos temas, que en muchas ocasiones tratan sobre el tiempo presente.

Por ello la selección previa y premeditada de contenidos ha sido una necesidad estructural de la enseñanza de la historia, especialmente si se propone ser "comprensiva" y no exclusivamente memorística. Pero es una tarea que se afronta pocas veces porque en definitiva supone un conflicto. ¿Cómo reconocer y seleccionar los contenidos "más relevantes" sin provocar, además, una discontinuidad en el "relato histórico"? 
Sin embargo, el análisis de un puñado de problemas muy significativos del presente durante el curso proporciona al profesorado un criterio de selección de contenidos no arbitrario, que además no produce esa discontinuidad, sino que, al revés, aporta consistencia a la explicación histórica. Se trata de escoger aquellos acontecimientos, fenómenos y procesos que a lo largo del tiempo han contribuido significativamente a la configuración actual del problema investigado, aquellos que lo explican históricamente.

El caso de la desigualdad mundial es un buen ejemplo. Sus orígenes se hallan en diversos fenómenos inscritos en la expansión transoceánica europea iniciada a finales del siglo XV: la explotación de personas y recursos americanos al servicio de las necesidades del viejo continente, la Trata trasatlántica de esclavos africanos, o el comercio triangular en su conjunto, que desarticularon globalmente regiones enteras de África y una buena parte de América. Ese proceso favoreció el ascenso económico y social de la burguesía europea y una inmensa acumulación de capital durante toda la Edad Moderna que, en lugares como el Reino Unido coadyuvó a la génesis de la Revolución Industrial a finales del XVIII. Ésta constituyó un nuevo factor de desigualdad mundial, no sólo porque generó una brecha visible aún hoy (pese a las potencias emergentes), sino porque exigió para su desarrollo una nueva fase imperialista. Desde finales del XIX hasta los años 60, 70 y 80 del siglo pasado la actividad económica de regiones y continentes enteros, particularmente África, estuvo al servicio de las necesidades occidentales, casi siempre por la fuerza de las armas. Las independencias de las colonias durante las décadas antes citadas supusieron la paulatina desaparición de vastos imperios y el nacimiento del Tercer Mundo. Sin embargo, pese a sus esfuerzos de solidaridad y cooperación (Conferencia de Bandung, Movimiento de Países no Alineados), esas independencias políticas no significaron el fin de la subordinación a las grandes potencias capitalistas en la gran mayoría de los casos. El subdesarrollo, la dependencia y el neocolonialismo, junto a otras fórmulas como la deuda externa, la Inversión Extranjera Directa, y la intervención militar, son los factores e instrumentos que las potencias occidentales emplean hoy para continuar explotando casi sin límites los recursos naturales y el trabajo de la mayor parte de la Humanidad. 
Cualquier profesor familiarizado con el currículo de la Historia del Mundo Contemporáneo sabría encontrar en el párrafo anterior al menos un tercio de los contenidos de esa materia. Sin duda, es una virtud extraordinaria del hilo de Ariadna, convertido así en el criterio de selección de contenidos. Pero pone de manifiesto una dificultad de consecuencias metodológicas: cuanto más relevante sea un problema del presente, más inclusivo será de contenidos, y por tanto exigirá más tiempo para su estudio, prolongándose la tarea durante varios meses.

En cualquier caso, y como ha expuesto el profesor Barros evocando los Annales, la aproximación al pasado para explicar un problema del presente promueve un cambio en la percepción de esos procesos históricos, que actúa directa y plenamente en el sistema de valores del alumnado. Así, la expansión europea de la Edad Moderna en América deja de ser una aventura casi heroica (como suele aparecer todavía en muchos libros de texto) para mostrar en plenitud sus caras más ocultas o minimizadas: el genocidio, la rapiña, la destrucción cultural... Igualmente la Trata esclavista, apenas citada en los manuales y completamente oculta en su auténtica dimensión, adquiere la entidad que realmente tuvo: la del mayor drama jamás conocido provocado por el hombre, y la del mejor negocio de la Edad Moderna para los comerciantes (incluidos algunos reyes y reinas) y para los propietarios de esclavos. $\mathrm{Y}$, ya en el presente, la convicción de muchos estudiantes acerca de que la carencia de recursos naturales es la principal responsable de la pobreza de multitud de países se desmorona totalmente al comprobar que la abundancia de determinados recursos es la primera razón del empobrecimiento, la desestructuración y los conflictos que sufren numerosas sociedades africanas. Finalmente, esos cambios en la visión del pasado desencadenan un giro radical en la mirada sobre el presente. La desigualdad mundial ya no es un "fenómeno de la naturaleza", ni los países enriquecidos lo son por su superior laboriosidad, inteligencia o suerte, sino gracias al pillaje que vienen practicando en medio mundo desde hace más de quinientos años. La consciencia de muchos alumnos se ha transformado al final del proceso.

El hilo de Ariadna así empleado posee otra virtud, que al mismo tiempo es una de las pretensiones más reiteradas de HaD: la práctica de la historia global, entendida como mundial y total. Explicar la desigualdad mundial supone penetrar en la Edad Moderna y en la Contemporánea. Exige conocer hechos de la historia 
económica, social, política y hasta de las mentalidades, y de casi todos los continentes. Y reclama acercarse a hechos y conceptos de geografía humana o de economía. Constituye una práctica coherente de la intradisciplinariedad historiográfica y de la interdisciplinariedad con otras ciencias sociales.

Para la discusión quedan fundamentalmente dos asuntos secundarios pero insoslayables. Por un lado es necesario dilucidar la secuenciación de los contenidos cuando se estudia un problema actual, o cómo se toma el hilo de Ariadna: si por el principio o por el final. ¿Se empieza a investigar la desigualdad mundial estudiando las razones del subdesarrollo y la dependencia de los países empobrecidos y del poder financiero e industrial de Occidente? ¿O se comienza por la construcción de los imperios transoceánicos europeos de la Edad Moderna? No se trata de opciones excluyentes: ambas se han ensayado cuando menos suficientemente. $Y$ es muy probable que eso dependa de las características del mismo problema que se investiga.

Por otro lado es necesario preguntarse si es imprescindible que los problemas pertenezcan al tiempo presente. De hecho ya se ha experimentado con cuestiones del pasado en Secundaria, donde además los contenidos históricos de $1^{\circ}$ y $2^{\circ}$ de ESO excluyen la contemporaneidad (aunque esto no suponga un obstáculo para aproximarse a la Edad Antigua con el objeto de encontrar las raíces de la actual desigualdad de género, por citar sólo un ejemplo). La pregunta cobra más sentido en los estudios universitarios, ya que los contenidos de muchas asignaturas están acotados por límites cronológicos o temáticos estrictos.

Una posible solución "salomónica", pero con fundamento en las fuentes tradicionales del currículo, consistiría en estudiar los problemas actuales sobre todo en las etapas no universitarias y afrontar más cuestiones del pasado en los centros superiores. No sólo se respondería mejor a la exigencia académica, sino que se estaría explotando una posibilidad didáctica: es muy probable que un estudiante universitario de historia se pueda motivar tanto estudiando incógnitas del pasado como del presente. 


\section{Enseñar historia reconstruyendo el pensamiento del alumnado}

El profesor Barros ha reclamado una renovación de los contenidos y de los métodos para el nuevo paradigma educativo de la historia. La organización de los contenidos en torno a problemas es una innovación, pero no es una novedad. La globalización de los contenidos es una práctica docente con un siglo a sus espaldas (centros de interés de Decroly) que, por tanto, ha podido mostrar su viabilidad, sus fortalezas y sus debilidades. Sin embargo, apenas si se hace en nuestro entorno. Lo mismo sucede con la investigación en el aula, sobre la que hay un acuerdo prácticamente unánime en HaD: los alumnos deben asumir el rol de investigadores. El mismo Carlos Barros lo ha postulado, aludiendo a Piaget y al constructivismo en general, para los que se debe enseñar experimentalmente.

Tampoco es una novedad que la enseñanza de la historia incorpore, cuando menos, algunos elementos aislados del proceso de investigación, reconociendo su trascendencia en la configuración de cierta clase de pensamiento histórico en cuanto al desarrollo de algunas destrezas intelectuales. La enseñanza tradicional ha convertido el comentario e textos históricos en la estrella de sus ejercicios prácticos, revelando de paso el principio cardinal de su sustrato teórico positivista: "la historia se hace con documentos". Al igual que el positivismo historiográfico reduce las fuentes a los documentos escritos, la enseñanza tradicional restringe todas las operaciones intelectuales y materiales que implica la indagación a situar a los estudiantes frente a un documento histórico. Pero no es ése el modelo de investigación en el aula que HaD demanda para el nuevo paradigma educativo.

¿Qué clase de investigación deben desarrollar entonces los alumnos? Para responder esta pregunta es necesario tener en cuenta dos premisas. En primer lugar, la respuesta no puede ser única. De una parte, es posible usar distintos métodos con un mismo grupo a lo largo del curso. De otra, no todos los métodos se pueden emplear por igual en todas las etapas del SE o, al manos, con el mismo rigor. En segundo lugar, en $\mathrm{HaD}$ hay suficiente consenso sobre algunos elementos que deben formar parte del método de investigación del alumnado, aunque se encuentren sujetos a una cierta discusión. Son tres piezas de un puzzle metodológico que debe completarse. 
La primera pieza es que la investigación debe centrarse en desentrañar un problema histórico significativo, del pasado o del presente, lo que además constituiría el primer paso del proceso de aprendizaje para los estudiantes. Aunque plantear un problema a un grupo pudiera parecer una tarea sencilla, no lo es tanto, sobre todo en las etapas no universitarias.

Una primera dificultad reside en la consciencia previa del alumnado sobre su existencia. En caso negativo es preciso recurrir a alguna estrategia como el contraejemplo, que permita revelar su existencia y su magnitud, al tiempo que se produce un primer conflicto cognitivo, como suele suceder con la escasez de regímenes democráticos en el mundo, que abre las puertas al problema: $¿$ (entonces) por qué hay tan pocas democracias en el mundo? En caso afirmativo, lo que ocurre con la desigualdad mundial, se puede realizar un planteamiento directo, aunque no está de más apoyarse en algún recurso (como una presentación de diapositivas) que delimite el problema y establezca su significado preciso.

Porque la segunda dificultad radica precisamente en ello: la comprensión compartida del problema. No todos los sujetos atribuyen el mismo significado al concepto de desigualdad mundial o al de democracia. Hay que asegurarse que todos los estudiantes van a estudiar "el mismo problema". Por ejemplo, muchos jóvenes interpretan la desigualdad mundial como la simple existencia de países muy pobres, pero no como las diferencias entre éstos y los más ricos. Y esa significación limitada del problema, que lo transforma en otro, condiciona estrechamente la formulación de las hipótesis y el estudio de información.

La siguiente pieza del rompecabezas metodológico, sobradamente subscrita en $\mathrm{HaD}$, es que, de acuerdo con el constructivismo, el aprendizaje consiste en la reconstrucción de los conocimientos y el pensamiento del alumnado. Por tanto, la explicitación de sus ideas previas juega un papel crucial en el proceso, al que se deben incorporar para su transformación. Este segundo paso es una necesidad para la que HaD no sólo cuenta con poderosas razones sicopedagógicas, sino también historiográficas ocupando un lugar preeminente en el Manifiesto. En su primer epígrafe se pone el acento en el protagonismo del sujeto que construye el saber histórico. $Y$ en el segundo reclama una actividad investigadora sustentada en el conocimiento no basado en fuentes del investigador, porque la historia también se hace con ideas, conjeturas, interpretaciones... 
Además, es tan importante poner en juego las ideas de los estudiantes sobre las razones del problema, como sus propuestas de estrategias de información y resolución. Es cierto que el núcleo del desarrollo competencial del alumnado se produce en el trabajo con las fuentes. Pero es asimismo indiscutible que su esfuerzo de planificación previa del "proyecto" constituye una actividad estratégica en ese sentido, como lo es igualmente la elaboración de una síntesis final. La confección de ese "plan de trabajo" (que también es propia de los historiadores) redunda muy positivamente en las competencias relativas a la autonomía personal y al auto aprendizaje, y resulta del todo imprescindible para organizar el trabajo con las fuentes.

Éste representa el tercer componente del puzzle y seguramente es el menos polémico, aunque también está parcialmente sujeto a discusión dentro y fuera de HaD. En él se despliega un conjunto de destrezas que pasan por la búsqueda, obtención y selección de distintos tipos de información, su análisis, transformación, contraste y síntesis. Y se puede llevar a cabo individualmente o en pequeños grupos, empleando técnicas de trabajo cooperativo como los "grupos de expertos". Es la fase de trabajo más prolongada y en ella se desarrolla la mayoría de las CCBB. Además de las antes citadas, entran en juego el tratamiento de la información, la comunicación lingüística, la competencia social, y, dependiendo de la temática y el formato de la información, la artística o la matemática.

El trabajo con fuentes supone una consecuencia metodológica que no pocos profesores tendrían dificultad en admitir: el destierro definitivo del libro de texto de las aulas de historia. Y al mismo tiempo significa la integración de las TIC, y particularmente Internet, como un recurso muy necesario para acceder a dichas fuentes. Los problemas relativos a la dotación y organización de los recursos informáticos en los centros de enseñanza, especialmente en Primaria y Secundaria, pueden suponer un cierto obstáculo para su empleo. Aunque igualmente lo es la complejidad de consultar algunos tipos de fuentes primarias en Internet (particularmente las archivísticas) y el predominio del relato tradicional en los sitios web de historia, ya advertido por el profesor Barros.

Pero el aprendizaje con fuentes implica otra consecuencia si se quiere "teórica", aunque con un profundo impacto vivencial. Significa la apertura del aula a la historia misma (mediante los documentos) y a la historiografía real (a través de la 
bibliografía) que en los libros de texto permanecen secuestradas bajo la apariencia de un formato y un discurso únicos.

En cualquier caso, la discusión en este ámbito podría girar en torno a la naturaleza de las fuentes: ¿primarias o secundarias? Es obvio que ambas tipologías son absolutamente imprescindibles, como lo son para los historiadores. Pero es lícito preguntarse en qué proporción cabría emplearlas en cada etapa del SE. A favor del uso de las primarias hay varias razones. Una es el carácter original de su información, no mediado por la labor de los historiadores, aunque sí de su autor. Otra es su mayor accesibilidad a través de Internet, con las salvedades antes expuestas. De todos modos existen colecciones impresas de documentos históricos, presentes aún en las librerías, que facilitan mucho la tarea. A favor de las fuentes secundarias cuentan sobre todo su abundancia y su (generalmente) mayor adaptación a la competencia general del alumnado.

Para completar este "rompecabezas metodológico" queda por determinar las características del segundo paso (la elaboración de un plan de trabajo) y la última fase, el producto final y su difusión social, que también forma parte del proceso de investigación desplegado por los historiadores. La estructura de ambos elementos está en función del método concreto que se practique, aunque su función es la misma en todos los casos.

Su adscripción al constructivismo pedagógico y sus principios historiográficos inclinan decididamente a HaD hacia los métodos globalizadores, desarrollados desde las propuestas constructivistas. Por un lado, efectivamente, suponen una organización globalizada de los contenidos. Por otro, todos ellos parten de una situación problemática real que los estudiantes deben resolver. Y, por ello mismo, no están despojados de la educación en valores humanos universales, que inicialmente las CCBB pretendían desplazar de las aulas. $Y$, sin embargo, contribuyen decididamente ( $y$ mejor que otros, a decir de muchos expertos) al desarrollo competencial, entre otras razones porque exigen una continua y coherente actividad del alumnado, como protagonista del proceso de aprendizaje bajo la tutela y orientación docentes.

Los centros de interés, los proyectos de trabajo, la resolución de problemas, los proyectos de investigación y acción... son métodos globalizadores. La elección de uno u otro puede depender del problema que se desea investigar. Pero sobre 
todo estriba en las características del alumnado. Algunos de ellos requieren una mayor autonomía y desarrollo competencial general, como la resolución de problemas, por lo que su uso parece más indicado en la enseñanza universitaria. Y otros, como los centros de interés, se han mostrado muy eficaces en las primeras etapas del SE.

También suponen algunas diferencias en la planificación del proceso de aprendizaje, comprometiendo en él habilidades intelectuales diferentes. En los proyectos de trabajo los estudiantes exponen lo que ya saben sobre el problema y lo que les gustaría o necesitarían saber para resolverlo. Así que el estudio de las fuentes está orientado a completar (y refutar, si es necesario) esos conocimientos previos. En los proyectos de investigación y acción, dichos conocimientos adquieren forma de hipótesis explicativas del problema. De modo que la fase de información está centrada en la verificación más o menos sistemática de esas conjeturas. En ambos caso, no obstante, es necesario elaborar regularmente informes parciales que vayan dando cuenta de los nuevos aprendizajes.

Todo esto comporta algunas diferencias en el producto final que deben hacer los estudiantes. En cualquier caso, debe contener una reconstrucción del proceso de trabajo general (desde el planteamiento del problema a la síntesis final) con sus dificultades, una síntesis explicativa del problema, integradora de los nuevos y los viejos conocimientos, una propuesta de soluciones al problema, y, si cabe, nuevas cuestiones relevantes para investigar suscitadas durante el trabajo. La diferencia más apreciable radica en la explicación del problema. En los proyectos de trabajo es sobre todo un texto expositivo, mientras que en los proyectos de investigación y acción posee un carácter más argumentativo.

Este producto final constituye un extraordinario recurso para la evaluación del aprendizaje y asimismo del proceso de enseñanza, debido a su naturaleza sintética. Pero también lo son todos los informes parciales $y$, antes, los distintos ejercicios de análisis y transformación de información. En este contexto el examen tradicional no tiene cabida, no solamente por su incoherencia "teórica", sino porque resulta absolutamente innecesario.

La cantidad de ejercicios, hechos por el alumnado desde el primer momento hasta el último, ofrece múltiples oportunidades de evaluación, que obviamente es continua en su sentido más genuino. Pero no es una cuestión de cantidad 
únicamente, sino también de calidad. Su diversidad tipológica es particularmente coherente con los posibles descriptores de la "competencia histórica" aquí propuesta, y con los de la mayoría de las CCBB. Pero se centra igualmente en las otras dos patas en las otras dos patas del nuevo paradigma educativo de la historia, los conocimientos y los valores, presentes desde la explicitación de las ideas previas hasta la síntesis final explicativa del problema y las propuestas de solución.

\section{Conclusiones}

Esta propuesta para un nuevo paradigma educativo implica enseñar historia para hacer futuro, estudiando problemas históricos relevantes mediante diversos métodos de investigación en el aula. Se basa en dos pilares principales. Por un lado, en los acuerdos más sólidos que la comunidad historiográfica de HaD ha consensuado desde su nacimiento hace más de cinco lustros hasta hoy. Por otro, en una praxis de la enseñanza de la historia que durante dos décadas se ha centrado en un modelo emancipador de enseñanza y aprendizaje.

Como toda propuesta puede y debe estar sujeta a discusión, no sólo de aquellos elementos que la misma reconoce controvertidos, sino también de aquellos otros que pudieran aparentar mayor consistencia. No obstante, sus principios epistemológicos y psicopedagógicos n o son precisamente novedosos, ya que algunos de ellos comenzaron a desarrollarse en la segunda mitad del siglo XIX. Pero la propuesta en su conjunto es una innovación, porque la práctica dominante en las aulas de historia aún hoy sigue siendo la tradicional.

En este tiempo presente, posterior al fin de la Guerra Fría, no interesa "otra" enseñanza de la historia. Es lo que mejor puede explicar la persistente impermeabilidad de las prácticas docentes a un conjunto de "veteranas innovaciones" de probado valor educativo. Por ello, no es de extrañar que las CCBB (una innovación desde arriba) hayan levantado tantas sospechas más que justificadas.

La presente propuesta de paradigma educativo puede calificarse de "revolucionaria" por su carácter netamente innovador. Pero sobre todo porque, 
siguiendo a Kuhn y su estructura de las revoluciones científicas, resuelve varios problemas que la enseñanza tradicional de la historia no ha podido atajar, cuando no los ha generado directamente. Supone enseñar una historia abierta a la realidad y al alumnado, una historia comprensible y aprehensible, útil y motivadora: una historia emancipadora.

Pero no es una receta milagrosa capaz de superar sin apenas esfuerzo algunos obstáculos muy presentes en determinados contextos sociales, suficientemente abundantes para convertir a España en uno de los países europeos con menor nivel cultural, con mayor abandono escolar temprano, y con mayor desinterés social por los asuntos educativos. Ni tampoco puede vencer fácilmente la cultura académica que hace a los graduados universitarios españoles no más competentes que los bachilleres coreanos.

Por todo ello es tan imprescindible como urgente diseñar, llevar a cabo, evaluar y difundir experiencias del nuevo paradigma de la enseñanza de la historia en los contextos sociales y nacionales más diversos. Es la mejor manera de contribuir a su ascenso y a la derrota del paradigma tradicional en las aulas, en las mentes de los niños y jóvenes, y también en las de sus profesores y profesoras. Y, para ello, los grupos de investigación en red de HaD constituyen una oportunidad muy poco común. Con ese empeño se han redactado estas páginas.

\section{Referencias:}

BARROS, Carlos. Propuestas para el nuevo paradigma educativo de la historia. Revista HISTEDBR On-line, Campinas, n.28, p. 2-24, dez. 2007.

Manifesto de Historia a Debate. http://www.hdebate.com/Spanish/manifiesto/idiomas manf/manifiesto had pt.htm 